\title{
AVALIAÇÃO DA ATIVIDADE ANTIBACTERIANA DE ASTER LANCEOLATUS WILLD. (ASTERACEAE) CONTRA STAPHYLOCOCCUS AUREUS
}

\author{
EVALUATION OF THE ANTIBACTERIAL ACTIVITY \\ FROM Aster lanceolatus Willd. (ASTERACEAE) AGAINST \\ Staphylococcus aureus
}

DIAS, J.F.G.; CUNICO, M.M.; MIGUEL, M.D.; MIGUEL, O.G.*

Laboratório de Fitoquímica, Departamento de Farmácia, Universidade Federal do Paraná (UFPR) * Autor para correspondência: Av. Pref. Lothário Meissner, 632, 80210-170, Curitiba, PR, obdulio@ufpr.br

\section{RESUMO}

Utilizando o método de bioautografia, avaliou-se a atividade antibacteriana de frações de Aster lanceolatus Willd contra cepas de Staphylococcus aureus. Os resultados demonstraram que a fração hexano e fração diclorometano apresentam atividade antibacteriana contra o microrganismo testado.

Palavras-chaves: fitoquímica; atividade antibacteriana; bioautografia; Aster lanceolatus.

\begin{abstract}
Using the bioautography method, the antibacterial activity of fractions from Aster lanceolatus Willd have been evaluated against stumps from Staphylococcus aureus. The results demonstrated that the hexane and diclorometane fractions present antibacterial activity against the tested microorganism.
\end{abstract}

Key words: phytochemistry; antibacterial activity; bioautography; Aster lanceolatus.

\section{INTRODUÇÃO}

A família Asteraceae compreende a maior família das angiospermas com aproximadamente 23.000 espécies, 1535 gêneros e representa aproximadamente $10 \%$ da flora mundial. Nos últimos 25 anos tem sido estudada em diversas áreas tais como anatomia, morfologia, ecologia, ontogenia, fitoquímica, estrutura macromolecular e citogenética (NAKAJIMA; SEMIR, 2001).

Plantas de hábito variado, ervas, subarbustos, trepadeiras ou excepcionalmente árvores. Constitui a maioria dos gêneros de plantas de pequeno porte. (JOLY, 1998). Apresenta distribuição cosmopolita, melhor representada em clima temperado e subtropical aonde não existam densas florestas. Espécies de vários gêneros são cultivadas para ornamentos e poucas para alimentação e produção de óleos (CRONQUIST, 1981). 
As plantas da família Asteraceae podem apresentar poliacetilenos, lactonas sesquiterpênicas, óleos essenciais, monoterpenos, alcalóides, látex com triterpenos (CRONQUIST, 1981), saponinas triterpenóides pentacíclicas (EVANS, 2002), antocianinas (TAKEDA; HARBORNE; SELF, 1986) e flavonóides (MARKHAM, 1982).

Conhecida como margarida-de-são-miguel, áster arbustiva e monte cassino, a Aster lanceolatus é uma planta de corte (FERRONATO, 2000) que apresenta atividade antibacteriana contra Streptococcus pyogenes, Salmonella typhimurium, Staphylococcus aureus (DIAS et.al., 2005; DIAS et.al., 2006) e atividade antifúngica contra Fusarium oxysporum e Cylindrocladium spathulatum (DIAS et.al., 2006).

\section{MATERIAL E MÉTODOS}

Os solventes e reagentes utilizados apresentaram grau de pureza analítico (Merck $\left.{ }^{\circledR}\right)$. A diluição das suspensões bacterianas foi realizada com salina estéril e a turbidez padronizada com o tubo 0,5 da escala de MacFarland (0,5mL de $\mathrm{BaCl}_{2} .2 \mathrm{H}_{2} \mathrm{O} 0,048 \mathrm{M}-1,75 \%$ peso/volume em $99,5 \mathrm{~mL}$ de $\mathrm{H}_{2} \mathrm{SO}_{4} 0,36 \mathrm{~N}-1 \%$ volume/volume).

Utilizou-se cultura bacteriana pura de $S$. aureus (ATCC 6538).

Para a atividade antibacterina utilizou-se o meio de cultura PCA (Plate Count Agar).

\subsection{MATERIAL VEGETAL}

A. lanceolatus foi coletada no mês de junho/2003. As exsicatas foram identificadas pelo botânico Dr. Gerdt Hatchbach do Museu Botânico Municipal (MBM) de Curitiba/PR e registradas neste museu sob o número 287.063.

\subsection{OBTENÇÃO DO EXTRATO ETANÓLICO E FRAÇÕES}

O extrato bruto das partes aéreas foi preparado com etanol $96^{\circ} \mathrm{GL}$ em aparelho de soxhlet (CARVALHO, 2001) até esgotamento. $O$ extrato obtido foi submetido à concentração em evaporador rotatório com pressão reduzida à temperatura de $50^{\circ} \mathrm{C}$ e $90 \mathrm{rpm}$. Em seguida armazenado em frasco âmbar, colocado no freezer por 24 horas e após, filtrado a vácuo em funil de Büchner. Após filtração, o extrato retornou ao frasco âmbar e foi armazenado na geladeira. Após o preparo do extrato, fez-se determinação de teor de sólidos depositando $1 \mathrm{~mL}$ de extrato bruto etanólico a ser analisado em cadinho pesado (triplicata), levando a estufa $100^{\circ} \mathrm{C}$ até peso constante e procedendo aos cálculos. $\mathrm{O}$ resultado é apresentado em quantidade de sólidos em $1 \mathrm{~mL}$. $\mathrm{O}$ teor de sólidos obtido foi $51,9 \mathrm{mg} / \mathrm{mL}$.

O extrato bruto etanólico foi fracionado por meio de partição líquido-líquido em aparelho de Soxhlet modificado (CARVALHO, 2001) com solventes de polaridade crescente, obtendo-se frações denominadas fração hexano (FH) e fração diclorometano (FDCM), com teores de sólidos $6,8 \mathrm{mg} / \mathrm{mL}$ e $17,2 \mathrm{mg} / \mathrm{mL}$ respectivamente.

\section{AVALIAÇÃO DA ATIVIDADE ANTIBACTERIANA}

Para a realização do teste de bioautografia utilizou-se o método adaptado de Romeiro (2001). Volumes de $3 \mu \mathrm{L}$ das frações hexano e diclorometano foram depositados sobre placas de sílica gel GF254 $(2,5$ x 5,0 cm) e submetidos ao sistema eluente hexano: acetato de etila (70:30). Após secagem das placas cromatografadas foram vertidos os meios de cultura contendo as suspensões bacterianas $(1 \mathrm{~mL})$ previamente padronizadas, e em seguida as mesmas foram incubadas a $35^{\circ} \mathrm{C}$. Após nítido crescimento dos microrganismos $(24 \mathrm{~h})$, observou-se ocorrência ou não, de halos de inibição, auxiliado pela revelação de cloreto de trifeniltetrazolium a $1 \%$ em ágar.

O teste foi realizado em duplicata.

\section{RESULTADO}

O resultado é apresentado por meio da figura 1, a qual ilustra os halos de inibição do crescimento do $S$. aureus pelas amostras testadas. 
FIGURA 1 - AVALIAÇÃO DAATIVIDADE ANTIBACTERIANA DA FRAÇÃO HEXANO E DICLOROMETANO DE A. Ianceolatus CONTRA $S$. aureus UTILIZANDO O MÉTODO DA BIOAUTOGRAFIA

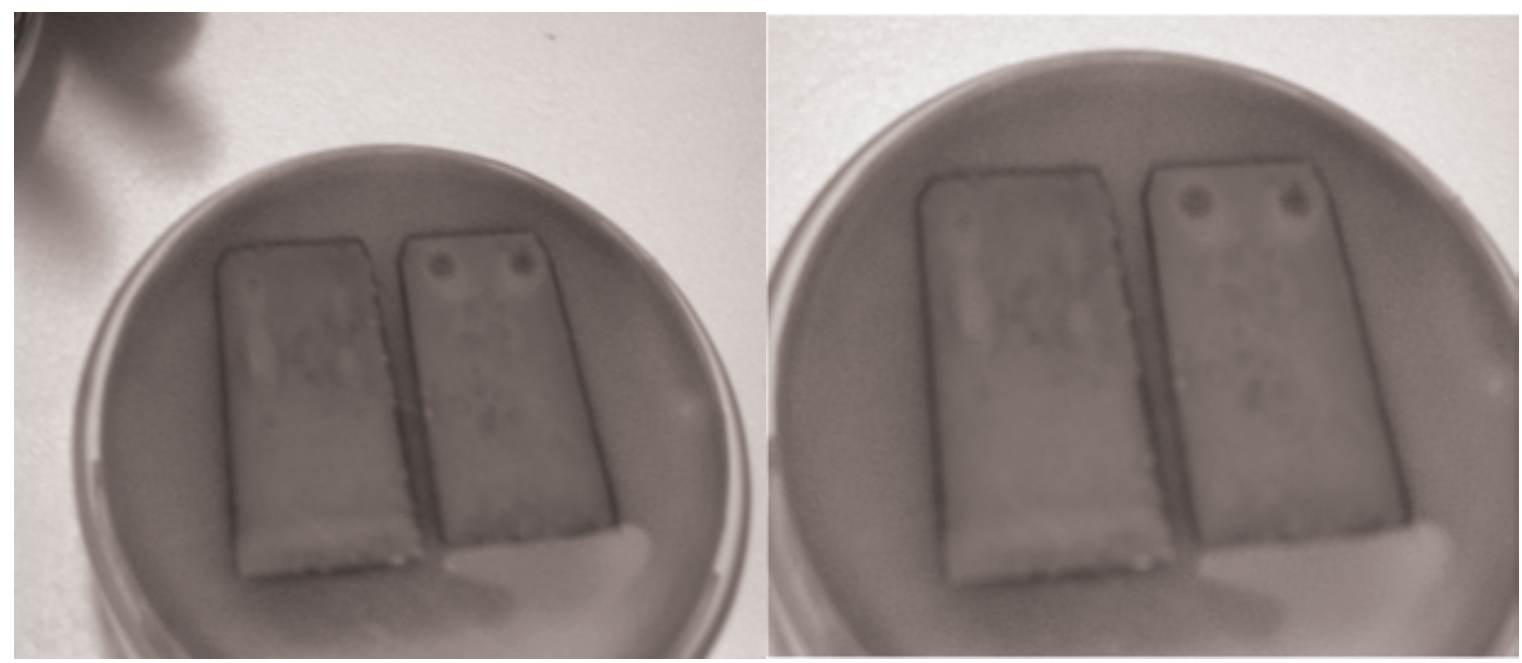

A figura 2 ilustra as amostras eluídas com o sistema eluente hexano: acetato de etila (70:30), reveladas com vanilina fosfórica e aquecimento.

FIGURA 2 - FRAÇÃO HEXANO E DICLOROMETANO DE A. lanceolatus ELUÍDAS COM O SISTEMA HEXANO: ACETATO DE ETILA (70:30) E REVELADAS COM VANILINA FOSFÓRICA E AQUECIMENTO

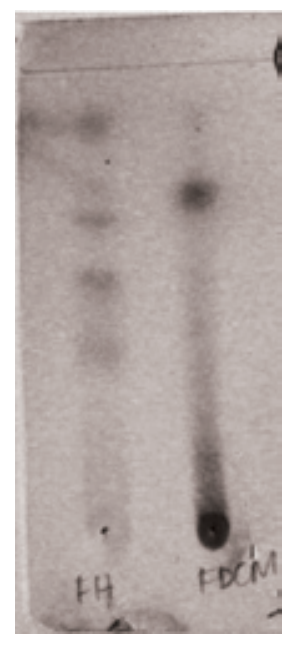

\section{CONCLUSÃO}

A atividade antimicrobiana de extratos brutos etanólicos de $A$. lanceolatus já tinha sido evidenciada em trabalhos anteriores (DIAS et.al., 2005; DIAS et.al., 2006).

Este trabalho demonstrou que as frações hexano e diclorometano de $A$. lanceolatus também apresentam atividade antimicrobiana, possivelmente decorrente de substâncias terpenóides, visto que houve revelação com vanilina fosfórica e aquecimento. 


\section{REFERÊNCIAS}

CARVALHO, J. L. DE S. Contribuição ao estudo fitoquímico e analítico de Nasturtium officinale R. BR., Brassicaceae. Curitiba, 2001. Dissertação de Mestrado em Ciências Farmacêuticas - Setor de Ciências da Saúde, Universidade Federal do Paraná.

CRONQUIST, A. An integrated system of classification of floring plants. New York: Columbia University Press, 1981. p.1021-1028.

DIAS, J.F.G. Estudo alelopático aplicado de Aster lanceolatus, Willd. Curitiba, 2005. Dissertação de Mestrado em Ciências Farmacêuticas - Setor de Ciências da Saúde, Universidade Federal do Paraná.

DIAS, J.F.G.; VIRTUOSO, S.; DAVET, A.; CUNICO, M.M.; FERRONATO, M.L.; BUFFON, M.C.M.; MIGUEL, M.D.; MIGUEL, O.G. Avaliação do efeito do extrato etanólico de Aster lanceolatus Willd. (Asteraceae) no controle do crescimento das bactérias da placa dentária. Estudo "in vitro". Visão Acadêmica. v.6, n.2, p. 20-23, 2005.

DIAS, J.F.G.; VIRTUOSO, S.; DAVET, A.; CUNICO, M.M.; MIGUEL, M.D.; MIGUEL, O.G.; AUER, C.G.; GRIGOLETTI-JUNIOR, A.; OLIVEIRA, A.B; FERRONATO, M.L. Atividade antibacteriana e antifúngica de extratos etanólicos de Aster lanceolatus, Willd., Asteraceae. Revista Brasileira de Farmacognosia. n.6, v.1, p.83-87, 2006.

EVANS, W.C. Trease and evans pharmacognosy. Toronto: W.B. Saunders, 2002. p.297.

FERRONATO, M.L. Aprimoramento de atributos comercialmente desejáveis em Aster sp cultivar White Master através do uso de reguladores do crescimento vegetal. Curitiba, 2000. Dissertação (Mestrado em Agronomia) - Setor de Ciências Agrárias, Universidade Federal do Paraná.

JOLY, A.B. Introdução à Taxonomia Vegetal. 12ed. São Paulo: Companhia Editora Nacional, 1998. p.628-638.

MARKHAM, K.R. Techniques of flavonoid identification. London: Academic Press, 1982. p. 1-93.

NAKAJIMA, J.N.; SEMIR, J. Asteraceae do Parque Nacional da Serra da Canastra, Minas Gerais, Brasil. Revista Brasileira de Botânica, v. 24, n.4, p. 471-478, 2001.

ROMEIRO, R. da S. Métodos em bacteriologia de plantas. Viçosa: Editora UFV, 2001. 279p.

TAKEDA, K.; HARBORNE, J.B.; SELF, R. Identification and distribution of malonated anthocyanins in plants of the Compositae. Phytochemistry, v.25, n.6, p.1337-1342, 1986. 